Article

\title{
DFT Modelling of Cu Segregation in Al-Cu Alloys Covered by an Ultrathin Oxide Film and Possible Links with Passivity
}

\author{
Pauline Cornette *, Dominique Costa * and Philippe Marcus \\ Institut de Recherche de Chimie Paris, CNRS—Chimie ParisTech (PSL) Research University, (UMR 8247), \\ Equipe de Physico-Chimie des Surfaces, 11 rue Pierre et Marie Curie, 75005 Paris, France; \\ philippe.marcus@chimie-paristech.fr \\ * Correspondence: pauline.cornette@chimie-paristech.fr (P.C.); dominique.costa@chimie-paristech.fr (D.C.); \\ Tel.: +33-1-4427-2525 (D.C.)
}

Received: 15 August 2017; Accepted: 7 September 2017; Published: 12 September 2017

\begin{abstract}
We modelled with Density Functional Theory (DFT) an Al-Cu alloy covered with a passive film, with several $\mathrm{Cu}$ concentrations (from the limit of the isolated atom to the monolayer) at the interface with the oxide, as well as Guinier-Preston 1 (GP1) zones. At low (respectively high) concentration, $\mathrm{Cu}$ segregates in the first (respectively second) metal layer underneath the passive film. The $\mathrm{Cu}$ monolayer is the most stable configuration $(-0.37 \mathrm{eV} / \mathrm{Cu}$ atom). GP1 zones were modelled, with a three-copper atom cluster in the alloy. The GP1 zone is slightly favoured with respect to the $\mathrm{Cu}$ monolayer under the oxide film. A low (respectively high) $\mathrm{Cu}$ concentration induces an electronic workfunction increase (respectively decrease) by $0.3 \mathrm{eV}$ (respectively -0.4 to $-0.6 \mathrm{eV}$ ) as compared to pure $\mathrm{Al}$. In contrast, without oxide, $\mathrm{Cu}$ segregation at the $\mathrm{Al}$ surface induces no workfunction change at low concentration and an increase of $0.3 \mathrm{eV}$ of the workfunction at high concentration. Thus, the presence of oxide modifies the expected tendency of workfunction increase by adding a more noble metal. For the studied models, no spontaneous electron transfer occurs to the $\mathrm{O}_{2}$ molecule.
\end{abstract}

Keywords: DFT; aluminium; Al-Cu alloy; corrosion; passive film; electronic workfunction; dioxygen reduction reaction

\section{Introduction}

$\mathrm{Al}$ alloys are widely used in aeronautics and space. To obtain good mechanical properties, alloying elements are used. Alloys of the 2000 series contain copper. On $\mathrm{Al} / \mathrm{Cu}$ alloys, the passive film is mainly composed of $\mathrm{Al}$ oxide/hydroxide [1,2]. Metal $\mathrm{Cu}$ enrichment underneath the passive film is a common situation due to the preferential oxidation of $\mathrm{Al}$ in $\mathrm{Al}-$-rich/ $\mathrm{Cu}$ alloy [3-7]. This $\mathrm{Cu}$ enrichment may alter the corrosion resistance properties of the passive film.

Since some years, theoretical studies based on first principles calculations have been developed to better understand corrosion and corrosion protection [6,8-13]. However, very few works exist on $\mathrm{AlCu}$ alloys. Hoshino et al. [14] showed that because of the strong hybridization of Aluminium $s p$ orbitals and metal $\mathrm{d}$ orbitals of transition atom in Al-M type alloys (where $\mathrm{M}$ is the transition metal), the stability of the bulk alloy depends on the medium range interactions of $\mathrm{M}$ atoms. Benali et al. [15] also investigate theoretically the $\mathrm{Al}-\mathrm{Cu}$ interactions in bulk phase at low $\mathrm{Cu}$ concentrations and found weak negative values of the mixing enthalpies, indicating a low tendency to form a solid solution at $\mathrm{T}=0 \mathrm{~K}$. Models of copper segregation within a given layer of (111) aluminium surface were proposed. The layer formation energy has a strong dependence on its composition and its position with respect to the surface. Thus, at low copper concentration (less than $50 \%$ per layer), the system is more stable when the doped layer is buried one layer under the surface, whereas for more than $50 \%$ of copper 
in the layer, the doped layer is more stable when buried two layers under the surface. Furthermore, at high copper concentration in the layer, the $\mathrm{Cu}$ atoms have a strong tendency to clusterize, in good agreement with the $\mathrm{Al}-\mathrm{Cu}$ phase diagram.

Some DFT theoretical studies have dealt with microstructure alloy phase in surface including metastable precipitates formed during cooling of the alloy, as Guinier-Preston (GP) zones [16,17]. A multiscale approach [18] was applied to model $\mathrm{Al}_{2} \mathrm{Cu}-\theta$ phase, and was validated by the comparison with the morphology and microstructural experimental data. It was followed by several ab initio studies of Wolverton et al. [19-23] and Zhou et al. [24]. Wolverton et al. [20] and Wang et al. [25] showed that copper monolayers were more stable than bilayers. They also found that the formation energies decrease in absolute value with respect to copper concentration increasing for both bilayer or monolayer. Other studies have analysed the atomic structure and the formation enthalpy of mixed Al-Cu layer [26-28]. Benali et al. [15] found that GP1 (one monolayer of $\mathrm{Cu}$ atoms on a $\{100\}$ lattice plane) and GP2 (multilayers of $\mathrm{Al}$ and $\mathrm{Cu}$ atoms) zones segregation one and two layers under the surface is favoured, GP1 being more stable than GP2.

None of the presented works have considered an alloy surface covered with oxide. However, it is important to understand the role of the presence of the oxide film on the thermodynamics of $\mathrm{Cu}$ segregation, and clusterization at the alloy/passive film interface. Several models of oxidized $\mathrm{Al}$ are found in the literature: Poberznik and Kokalj [13] explained why the O monolayer on $\mathrm{Al}$ has attractive lateral interactions which allows the oxide growing. Lantony et al. [29] studied the first steps of $\mathrm{O}$ adsorption on $\mathrm{Al}$, and the formation of a $\gamma$-like ultrathin film. Costa et al. [6] modelled an hydroxylated $\gamma$-(111) $\mathrm{Al}_{2} \mathrm{O}_{3}$ film on $\mathrm{Al}(111)$. Baran et al. [30] studied $\gamma-\mathrm{Al}_{2} \mathrm{O}_{3}$ films on $\mathrm{Al}$ and found that the electronic properties of the film depend on the oxide thickness.

In the present work, we present a study of $\mathrm{Cu}$ location and concentration in the alloy covered with a passive film composed of hydroxylated $\mathrm{Al}_{2} \mathrm{O}_{3}$. The energetics of $\mathrm{Cu}$ segregation, and monolayer formation underneath the passive film is calculated. In addition, structural phases as GP zones are considered. The electronic analysis of each system is performed in order to understand the potential influence of the alloy composition underneath the passive film on the passivity. Mainly, the electronic workfunction is taken as an indicator of the cathodic corrosion resistance. Indeed, as stated by Huang et al. [31], this parameter is a measure of the difficulty for changing the electronic state of the solid, which is related to the corrosion behavior of materials. A higher work function corresponds to a more stable electron state and thus a higher resistance to corrosion reactions. Huang et al. [31] also established the link between the electron workfunction and macroscopic properties, as interfacial bond strength and mechanical properties.

\section{Methods}

\subsection{Calculations}

All calculations were performed using the periodic density functional theory (DFT) method based on the generalized gradient approximation (GGA) [32], employing the Perdew, Burke and Ernzerhof (PBE) [33] exchange-correlation functional as implemented in the plane-wave program Vienna ab initio simulation package (VASP) [34].The projector-augmented wave (PAW) potentials [35,36] were used for the core electron representation with a PAW core radius of $1.52 \AA$ for oxygen.

For the bulk materials, the simulation supercells contained 4 atoms for $\mathrm{Al}$ and $\mathrm{Cu}$, and 120 atoms for $\gamma-\mathrm{Al}_{2} \mathrm{O}_{3}(111)$. A converged $\mathrm{K}$-points mesh of $(6 \times 6 \times 6)$ was used for each bulk $\mathrm{Al}, \mathrm{Cu}$ and $(4 \times 1 \times 4)$ for $\mathrm{Al}_{2} \mathrm{O}_{3}$. Within this approach, the bulk lattice constants are $\mathrm{a}=4.05 \AA$ for $\mathrm{Al}, \mathrm{a}=3.63 \AA$ for $\mathrm{Cu}$, and $\mathrm{a}=9.78 \AA, \mathrm{b}=8.32 \AA$ and $\mathrm{c}=13.56 \AA\left((111) \gamma-\mathrm{Al}_{2} \mathrm{O}_{3}\right)$ in good agreement with experimental values and previous studies $[6,15]$. The unit cell of the supported oxide film model for segregation study has dimensions of $\left(8.58 \times 9.90 \times 58 \AA^{3}\right)$ and a surface of $0.85 \mathrm{~nm}^{2}$. For GP1 zone, the dimensions of the unit cell are $\left(8.58 \times 19.81 \times 58 \AA^{3}\right)$ with a corresponding surface area of $1.7 \mathrm{~nm}^{2}$. 
For each calculation, the quality of the basis set is determined by a single parameter, the energy cutoff $\left(E_{\text {cut }}\right)$. In this work, we used $E_{\text {cut }}=520 \mathrm{eV}$ and a smearing $\sigma=0.01 \mathrm{eV}$ was applied. A dipolar correction was applied along the $z$ axis. The integration in reciprocal space was performed with a Monkhorst-Pack [37] grid $(3 \times 3 \times 1)$. Dispersion forces were considered in the D2 Grimme approach [38]. Geometry optimizations performed all along this work were considered converged when the forces were inferior to $10^{-4} \mathrm{eV}$ per cell.

\subsection{Models}

The slab containing 8 metallic aluminium layers supporting a $9 \AA$ thick hydroxylated aluminium oxide film is shown in Figure 1. The oxide film has a stoichiometry of $\mathrm{Al}_{2} \mathrm{O}_{2.57}$ and exhibits a hydroxyl density of $14.4 \mathrm{OH} / \mathrm{nm}^{2}$ [6,39]. It is composed of $\gamma$-alumina (111). This face is polar, with alternance of oxygen planes and Al planes. The Al planes contain Al with either octaedric or tetrahedral coordination. We showed in our previous work that the oxide layer has an Al octaedric plane at the interface with the metal. This $\mathrm{Al}$ plane is named here the interfacial Al layer. It was shown in our previous work that the $\mathrm{Al}$ atoms of this plane have a metallic character.

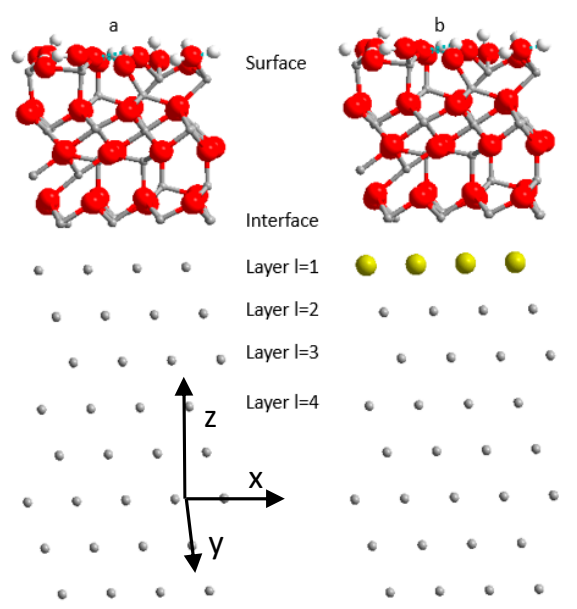

Figure 1. Slab model (a) Aluminium oxide supported by pure aluminium; (b) Aluminium oxide supported by an alloy with a full layer of copper in position $l=1$. Aluminium atoms are in grey, copper atoms in yellow, oxygen atoms in red and hydrogen atoms in white.

The first full metal layer under this $\mathrm{Al}$ interface layer is referred here with the index $l=1$, then $l=2$ represents the next underneath metal layer and $l=3$ the third metal layer. The layer $l=4$ is considered as a bulk layer.

To study the effect of alloying with $\mathrm{Cu}, 1,2,3,4,5,10$ and 12 copper atoms by layer or a copper concentration in the layer of $8,16,25,33,42,83$ and $100 \%$ respectively were considered. The $\mathrm{Cu}$ atoms were placed in the layer in the most homogeneous possible repartition and trying to avoid small clusters formation.

The models of the GP zones are shown in the corresponding Section 3.4.

\subsection{Electronic and Charge Analysis}

DOS curves were obtained using a grid of $3 \times 3 \times 1$ K-points. The electronic work function was obtained by analysing the LOCPOT file provided in VASP, and reporting the difference between the vacuum potential near the surface and the metal Fermi level. Our periodic cells exhibit two different surfaces, the pure metal surface at the bottom and the oxide film at the top. Thus, we could calculate directly the electronic workfunction difference with the pure metal, measuring the difference between the vacuum level near the surface of the oxide film and the vacuum level near the surface of the 
metal. For the $\mathrm{Al}(111)$ surface, a calculated value of $4.1 \mathrm{eV}$ was obtained, to be compared with the experimental value of $4.25 \mathrm{eV}$ [40].

In preliminary tests, we increased the $\mathrm{Al}(111)$ slab thickness up to nineteen layers, as recommended in reference [15]. We concluded that a six layer slab is enough to reproduce the main electronic features of the metal. In the present study, a slab of eight metallic layers is used. We also checked the variation of the electronic workfunction with the vacuum height. All tests confirmed that the model used was sufficiently robust.

Atomic charges were obtained using the Bader charge analysis [41]. With this method the mean $\mathrm{Al}$ and $\mathrm{O}$ charges in bulk $\mathrm{Al}_{2} \mathrm{O}_{3}$ are $+2.49 \mathrm{e}$ and $-1.66 \mathrm{e}$, respectively. This allowed us to calculate the charge transfer between the metal and the oxide film.

\subsection{Energetics}

The segregation energy corresponds to the driving force for surface segregation. It is defined as the variation of energy per atom of copper resulting from the exchange of one or more copper atoms in a volume of layer transferred to the surface. It is calculated by:

$$
E_{\text {seg }}\left(c_{l}\right)=\frac{E\left(c_{l}, x\right)-\lim _{l \rightarrow \infty} E\left(c_{l}, x\right)}{c_{l}}
$$

In this equation, $c_{l}$ is the concentration of copper in the layer $l$ and $E\left(c_{l}, x\right)$ the total energy of a semi-infinite alloy $\mathrm{Al}_{(1-x)} \mathrm{Cu}_{x}$ at a copper concentration $c_{l}$ in the layer. The energy of segregation tends to 0 when $l$ approaches infinity.

As explained in the reference [15], the segregation energy is a way to measure the copper tendency to form aggregates in a given layer. At the lowest concentration of copper, we substituted one atom by layer and buried this atom to the layer $l=4$. The equivalent concentration is therefore $c_{l}=1 / 12$ or $8 \%$ per layer or $0.93 \%$ by volume. At this concentration, the $\mathrm{Cu}-\mathrm{Cu}$ distance is $8.3 \AA$. Hoshino et al. [14,42] showed using theoretical calculations that the $\mathrm{Cu}-\mathrm{Cu}$ interaction in $\mathrm{Al}$ is negligible for $\mathrm{Cu}$ atoms distances are $>5.5 \AA$. To this respect, we can consider this concentration as the infinite dilution limit for copper. The segregation energy is the difference between the energy of substituting $\mathrm{Nl} \mathrm{Al}$ atoms by $\mathrm{Cu}$ atoms in a layer, and the same in the bulk at infinite dilution and is written:

$$
E_{\mathrm{seg}}\left(\frac{N l}{N}\right)=\frac{E_{\mathrm{slab}}(N l)-E_{\mathrm{slab}}(0)}{N l}+\mu_{\mathrm{Al}}\left(x_{\mathrm{Al}} \rightarrow 1\right)-\mu_{\mathrm{Cu}}\left(x_{\mathrm{Cu}} \rightarrow 0\right)
$$

Here, $N$ is the total number of atoms per layer, $N l$ the copper atom number per layer, $E_{\text {slab }}(N l)$ the slab total energy for $N$ copper atoms, $\mu_{\mathrm{Al}}$ is the chemical potential of aluminium in pure aluminium (here $\mu_{\mathrm{Al}}\left(x_{\mathrm{Al}} \rightarrow 1\right)$ is equivalent to the cohesive energy in $\left.\mathrm{Al}\right)$ and $\mu_{\mathrm{Cu}}\left(x_{\mathrm{Cu}} \rightarrow 0\right)$ the chemical potential of copper at infinite dilution in the alloy $\mathrm{Al}_{(1-x)} \mathrm{Cu}_{x}$. The chemical potential of $\mathrm{Al}$ and $\mathrm{Cu}$ are evaluated as in the reference [15]. Note that for an isolated $\mathrm{Cu}$ atom in the fourth layer, the energy of $\mathrm{Cu}$ dilution in $\mathrm{Al}$ is $-0.147 \mathrm{eV}$, a value very near that of $\mathrm{Cu}$ dilution in bulk $\mathrm{Al}(-0.14 \mathrm{eV})$. This difference $(0.007 \mathrm{eV})$ is small enough to allow us to consider that $\mathrm{Cu}$ in the fourth layer is our internal reference for $\mathrm{Cu}$ in a dilute solid solution.

At increasing copper concentration, $\mathrm{Cu}$ aggregates form with interacting $\mathrm{Cu}(\mathrm{Cu}-\mathrm{Cu}$ distances $<5.5 \AA$ ). In this case, applying Equation (2) results into the sum of aggregation and segregation energies. Therefore, to get the segregation energy only, the solid reference energy taken is that of the aggregate formation in the bulk. In other words, we separate the aggregation energy from the segregation energy and consider the segregation of an already formed $\mathrm{Cu}$ aggregate from the bulk to the surface. The segregation energy is thus calculated by:

$$
E_{\text {seg }}\left(\frac{N l}{N}\right)=\frac{E_{\text {slab }}(N l)-E_{\text {slab }}\left(N l_{b}\right)}{N}
$$


In this equation $\mathrm{Nl}$ is the number of copper atoms in the layer $l, N$ is the number of atoms per layer, $E_{\text {slab }}(N l)$ the slab energy and $E_{\text {slab }}\left(N l_{b}\right)$ the energy of the slab where copper is buried in the layer $l_{b}, l_{b}$ being large enough to converge to the value of the crystal. $l_{b}=4$ is considered as the representative configuration of the condensed phase volume.

In the present work, we used Equation (2) for studying the GP zone formation. Equation (3) at higher concentrations was used for the other situations, i.e., specifically $\mathrm{Cu}$ segregation. Obviously, at low $\mathrm{Cu}$ concentrations, Equations (2) and (3) are equivalent.

\section{Results}

We study $\mathrm{Al}$ based alloy with different $\mathrm{Cu}$ locations and concentrations in the first metallic layers under the oxide film, and GP zone, all models being covered with an aluminium oxide film. We substituted one or several aluminium atom(s) by copper in the first, second, third or fourth layer (taken as a reference of the bulk) of the (111) surface under the oxide film. We increased the copper concentration in each layer up to form a copper complete layer and varied its position from the surface to the bulk. Thus, by simply comparing the energy in the layer $l=1,2$ or 3 with respect to the energy of $\mathrm{Cu}$ in $l=4$, we could obtain the energy of $\mathrm{Cu}$ segregation from the bulk towards the third, second and first layer underneath the interface with the oxide (Equation (3)).

\subsection{Energetics of $\mathrm{Cu}$ in $\mathrm{Al}(111)$ Covered by an Oxide Layer as a Function of $\mathrm{Cu}$ Concentration and Location}

We first present the overall energetic results. As mentioned in the introduction, two trends were identified in literature on metallic $\mathrm{Al}$ [15]: The tendency for $\mathrm{Cu}$ aggregation, and that of $\mathrm{Cu}$ segregation towards the surface. Here, we study if these general trends observed on $\mathrm{Al}(111)$ are maintained when an oxide layer covers the surface. Figure 2 reports the energies of $\mathrm{Cu}$ segregation and/or aggregation in the first layers under the oxide film, calculated with Formula (2). The reference is one $\mathrm{Cu}$ atom in the $l=4$ layer, which is the internal reference for $\mathrm{Cu}$ at the infinite dilution limit in the $\mathrm{Al}$ bulk (Equation (2)). For comparison, we also reported data that we calculated for the oxide-free $\operatorname{Al}(111)$ surface.

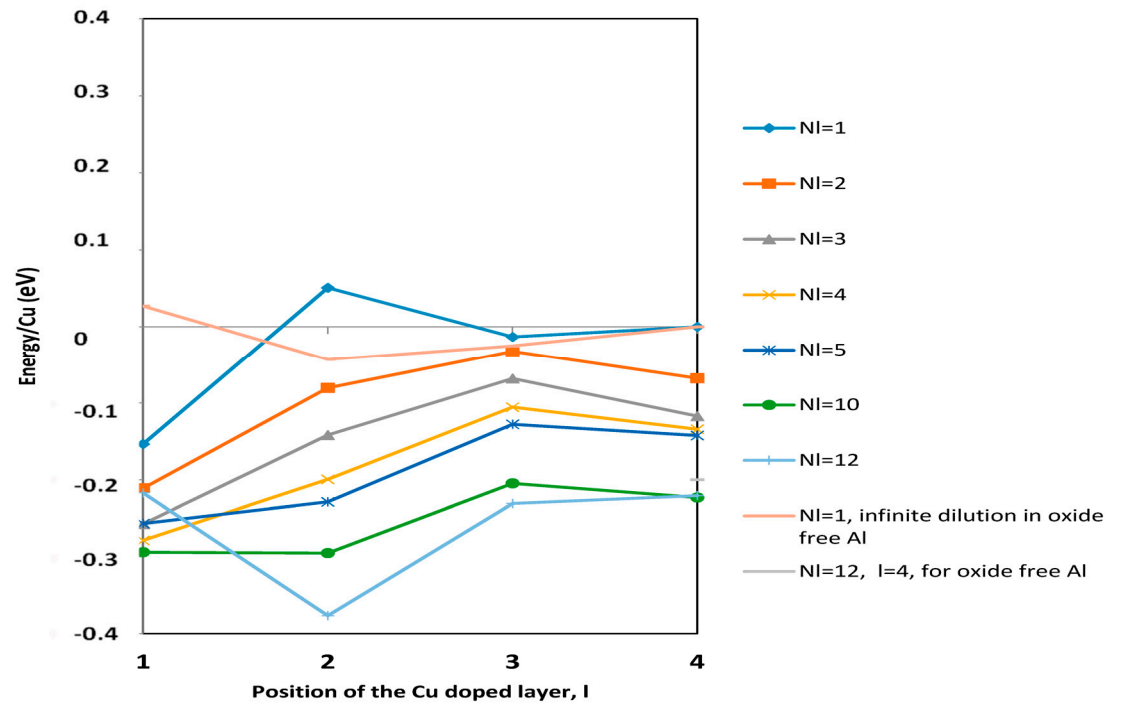

Figure 2. Energy of $\mathrm{Cu}$ segregation and aggregation/ $\mathrm{Cu}$ atom (calculated with Formula (2)) in the $\mathrm{Al}(111)$ slab covered with the oxide film as a function of the location of $\mathrm{Cu}$ underneath the oxide-metal interface, in the layer $l$. $l=1$ is the first layer underneath the metal oxide interface, and $l=4$ is the fourth layer underneath the metal-oxide interface, as shown in Figure 1. $\mathrm{Nl}$ is the number of $\mathrm{Cu}$ atoms in the layer (see Formula (2)). Data obtained for the oxide-free $\mathrm{Al}(111)$ surface are also indicated. As stated in the text, the reference energy is the isolated $\mathrm{Cu}$ atom in the $l=4$ layer, which is representative of the $\mathrm{Cu}$ infinite dilution in bulk Al. 
In the $l=4$ layer, we found that increasing the $\mathrm{Cu}$ concentration up to the $\mathrm{Cu} \mathrm{ML}$ is energetically favourable. Without oxide, we found nearly the same energy of $\mathrm{Cu}$ ML formation $(-0.15 \mathrm{eV}$ without oxide, $-0.18 \mathrm{eV}$ with oxide). The tendency of energy gain with increasing $\mathrm{Cu}$ concentration in a given layer is observed also for the $l=3$ and $l=2$ layers. We observe the stabilization of the system by $\mathrm{Cu}$ aggregation to form a full layer underneath the $\mathrm{Al}$ /oxide interface, the most stable configuration being a full $\mathrm{Cu}$ layer in $l=2$ position. But for $l=1$, at the interface with the oxide, albeit all $\mathrm{Cu}$ concentrations are energetically favored with respect to infinite dilution in the bulk, the full $\mathrm{Cu}$ layer is slightly less stable than partial $\mathrm{Cu}$ contents with $\mathrm{Nl}=10,4$ and $5 \mathrm{Cu}$ atoms.

In the next paragraph we focus on the $\mathrm{Cu}$ segregation energy.

\subsection{Copper Segregation at the Interface with the Passive Film}

\subsubsection{Energy of Segregation}

Figure 3 shows the segregation energy relative to the layer position for different $\mathrm{Cu}$ concentrations. $\mathrm{Cu}$ segregation from $l=4$ to the first metallic plane $(l=1)$, just under the oxide film, is always favourable. For concentrations higher than $8 \%$ per layer $(N l=1)$, segregation to $l=2$ is also favoured, whereas segregation of a single $\mathrm{Cu}$ atom from $l=3$ to $l=2$ is unfavorable by $0.05 \mathrm{eV}$. Figure $3 \mathrm{~b}, \mathrm{c}$ show that the energy of segregation of $\mathrm{Cu}$ from the bulk to the $l=2$ plane decreases with increasing concentration, whereas the reverse is observed in $l=1$ plane. Comparing energies in $l=2$ and $l=1$, segregation from $l=2$ to $l=1$ is favoured for $\mathrm{Nl}=1,2,3,4$ and $5 \mathrm{Cu}$ atoms in the plane, athermic for $\mathrm{Nl}=10 \mathrm{Cu}$ atoms and endothermic for a full $\mathrm{Cu}$ layer. Copper location $l=3$ is still slightly different from bulk.

(a)
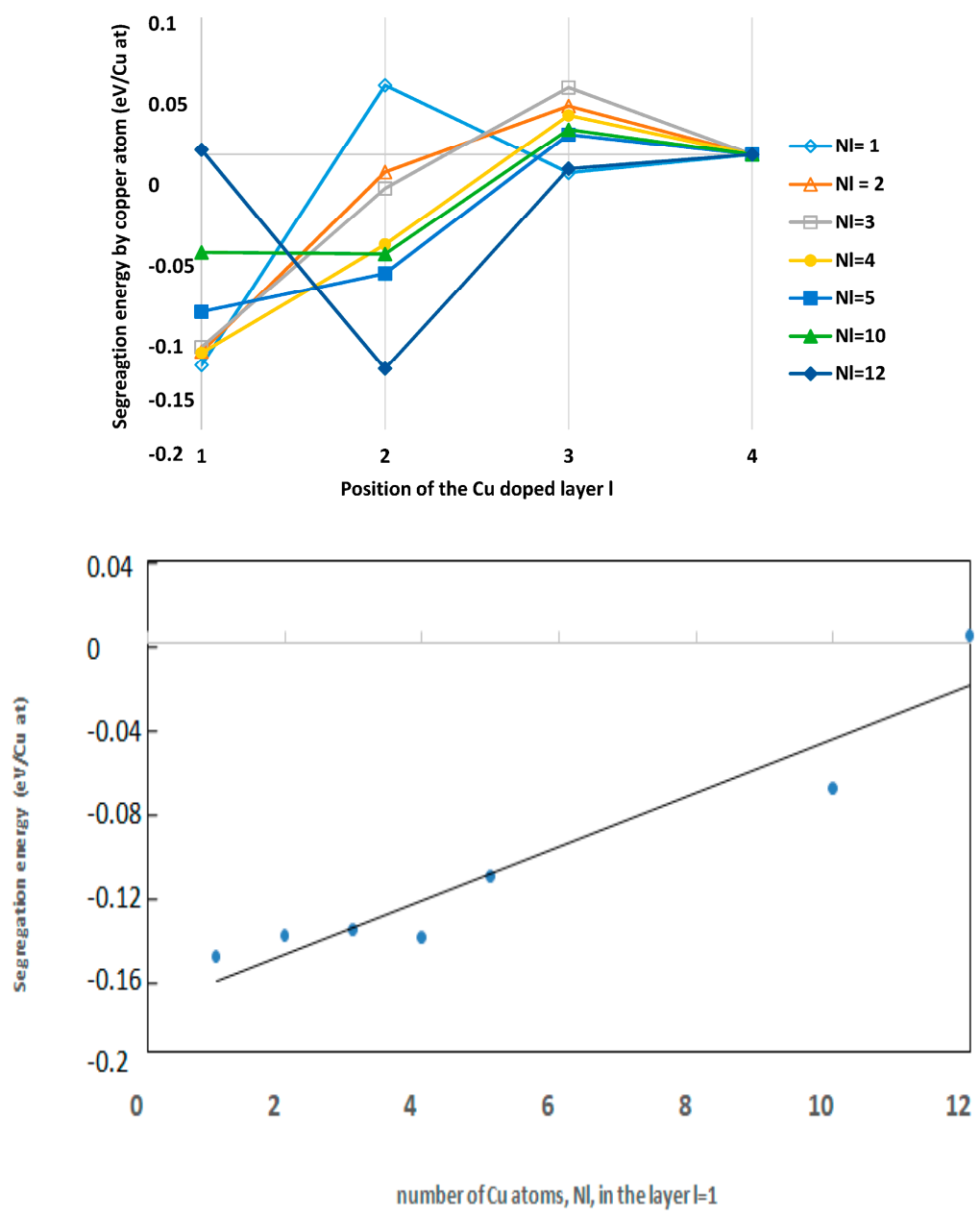

Figure 3. Cont. 


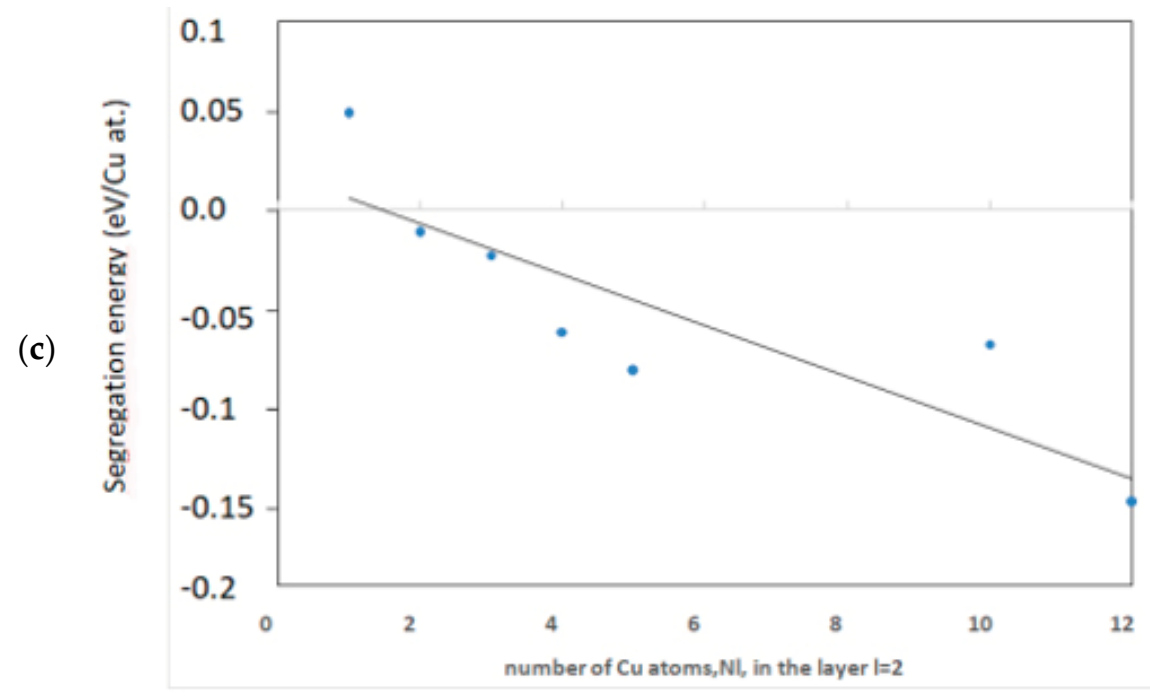

Figure 3. (a) Evolution of the segregation energy of copper to the $\mathrm{Al}(111) / \mathrm{Al}_{2} \mathrm{O}_{3}$ interface for different concentrations with respect to the doped layer position 1 in the slab. With respect to Figure 2, Figure $3 a$ shows results calculated with Formula (3), thus, for each position and concentration, the energy reference is the same concentration of $\mathrm{Cu}$ in the $l=4$ position; (b) Segregation energy of copper in the layer $l=1$ as a function of the number of $\mathrm{Cu}$ atoms in the layer. $\mathrm{Nl}$, formula (3); (c) Segregation energy of copper in the layer $l=2$ with respect to the number of $\mathrm{Cu}$ atoms in the layer $\mathrm{Nl}$ Formula (3). Lines are guides to the eye.

It is interesting to note that the favoured positions for $\mathrm{Cu}$ move closer to the interface in presence of the oxide film. It was shown that without the oxide film, the favoured positions are in $l=2$ and $l=3$ plane [15]. The first aluminium layer of the oxide film might stabilize the copper atoms close to the interface. Indeed, this interface layer has metal properties and can be considered as a layer with vacancies (10 aluminium atoms against 12 in the metal plane); thus the nature of the first neighbours of the $l=1$ layer of the oxide covered alloy is not so different from the environment of the $l=2$ layer in the uncovered alloy. The most stable configuration thus consists in a $\mathrm{Cu}$ monolayer under one $\mathrm{Al}$ metal layer $(l=2)$.

We have highlighted a segregation phenomenon to the metal/oxide interface for all $\mathrm{Cu}$ concentrations, with a stabilisation in $l=1$ at low $\mathrm{Cu}$ concentration, and in $l=2$ for concentrations higher than $\mathrm{Nl}=1$, i.e., $8 \% \mathrm{Cu}$ per layer.

\subsubsection{Charge Analysis and Electronic Workfunction}

$\mathrm{Cu}$ Located in the $l=1$ Layer

Figure 4 shows the average electron charge per atom of the plane $l=1$ and of the $\mathrm{Al}$ atoms of the oxide interface, as a function of the copper concentration in the first metallic layer $l=1$. The amount of charge evolves monotonously with the $\mathrm{Cu}$ concentration: The more substitution of aluminium by copper, the more negative charge is transferred to the layer $l=1$. For a full $\mathrm{Cu}$ layer at $l=1$, a charge transfer of $0.87 \mathrm{e} / \mathrm{Cu}$ occurs from the oxide layer towards the $\mathrm{Cu}$ layer. This charge transfer originates from the oxidation of the $\mathrm{Al}$ interface layer from $\mathrm{Al}^{+1.6}$ to $\mathrm{Al}^{2+}$ (Figure 4), which nearly recover the charge of $\mathrm{Al}$ ions in $\mathrm{Al}_{2} \mathrm{O}_{3}$ (for $\mathrm{Al}^{2.5+}$ in bulk $\mathrm{Al}_{2} \mathrm{O}_{3}$ ). The other layers of the oxide film are not impacted. The charge transfer from the interface layer to $l=1$, induces the formation of a net dipole; an electric field attractive for the electrons originating from the metal is created between the interface aluminium positively charged and the negative copper of the metallic plane. This field induces a workfunction decrease (see Figure 5). 


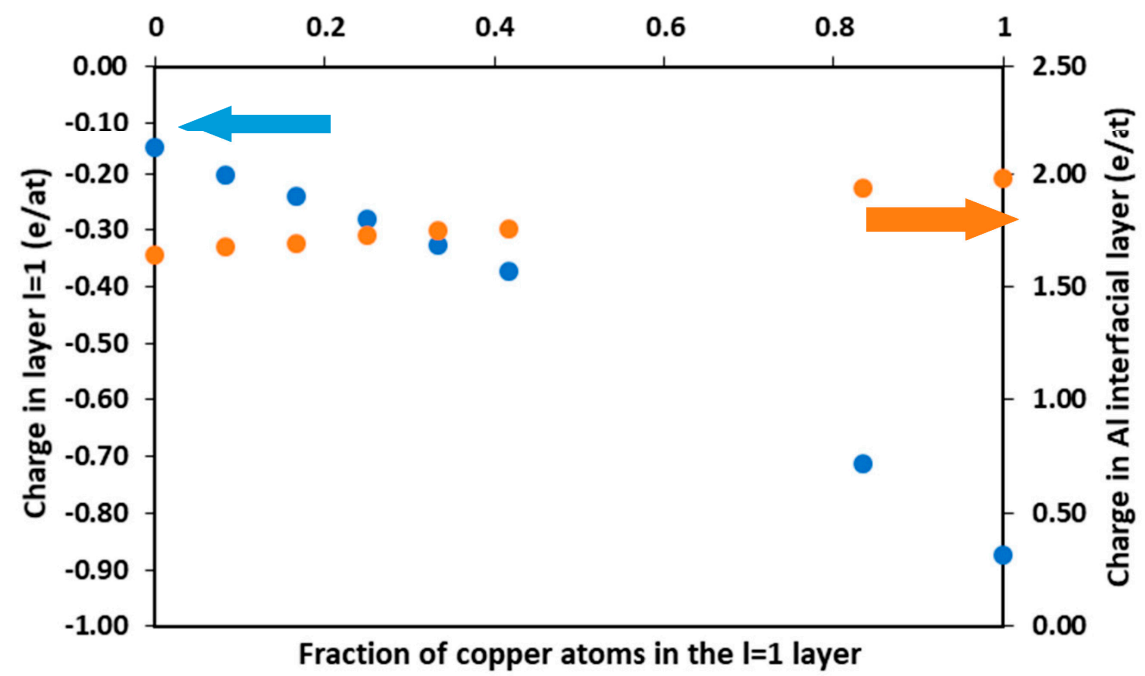

Figure 4. Evolution of the average electron charge per atom in the interfacial Al layer (orange, right $y$ axis) and the layer $l=1$ (blue, left $y$ axis) depending on the copper fraction in the metallic layer $l=1$.

(a)
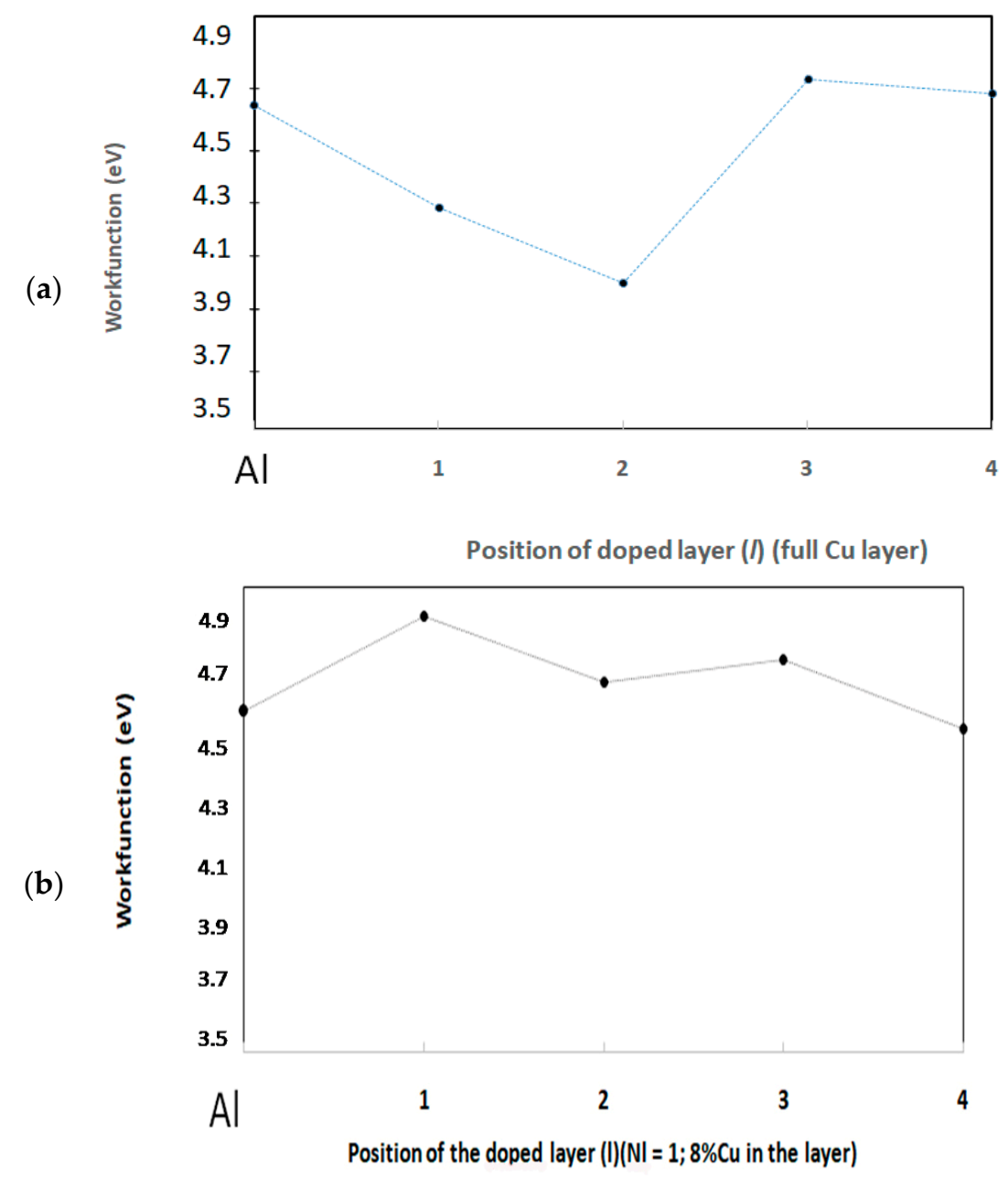

Figure 5. Workfunction (eV) of the alloys (a) for a complete monolayer of copper; (b) for $\mathrm{Nl}=1 \mathrm{Cu}$ atom in the layer, a concentration of $8 \% \mathrm{Cu}$ in the layer, infinite dilution limit, as a function of the position of

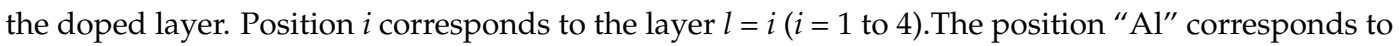
pure aluminum. 
We mention for comparison that in the absence of oxide, the workfunction of $\mathrm{Al}(111)$ (calculated as 3.98 in the present work) is not modified by the presence of $\mathrm{Cu}$ at low concentration at the surface, and is increased by $0.3 \mathrm{eV}$ when a full $\mathrm{Cu}$ monolayer is at $l=1$. Indeed, $\mathrm{Cu}$ being more noble than $\mathrm{Al}$, has a workfunction of $4.6 \mathrm{eV}$ higher than that of $\mathrm{Al}(4.2 \mathrm{eV})$, an increase in electronic workfunction is expected when $\mathrm{Cu}$ is at the $\mathrm{Al}$ surface.

We thus observe a drastic change in the electronic properties of the $\mathrm{Cu}$-doped $\mathrm{Al}(111)$ surface in the presence of an oxide layer, the charge transfer from metal/oxide interfacial $\mathrm{Al}$ to $\mathrm{Cu}$ inducing a lowering of the electronic workfunction.

Full Cu Layer at Depths $l=2,3,4$

When a full $\mathrm{Cu}$ layer is in the position $l=2$, a charge transfer occurs between the Cu plane and the $l=1$ layer of $\mathrm{Al}$ metal with a value of $0.34 \mathrm{e} /$ at charge (not shown). The charge transfer to the $\mathrm{Al}$ ions of the oxide at the interface with the metal is $-0.05 \mathrm{e} / \mathrm{at}$, thus the oxide is not affected by the presence of the $\mathrm{Cu}$ layer. The workfunction (Figure 5a) is lower and the system is more stabilized. Again, the reserve is observed on the $\mathrm{Al}(111)$ surface without oxide, for which we calculate a workfunction increase of $0.18 \mathrm{eV}$ with respect to pure $\mathrm{Al}(111)$ for a full $\mathrm{Cu}$ layer at $l=2$.

When the full $\mathrm{Cu}$ layer is in position $l=3$ and $l=4$, we observe a charge transfer to the above neighbour plane, but no charge transfer to the interface $\mathrm{Al}$, and in consequence, no significative modification of the workfunction with respect to pure Al (all calculated workfunctions are around $4.6 \mathrm{eV}$ ) (Figure 5a). The same is found without oxide.

\section{$\mathrm{Cu}$ at Low Concentration}

At very low $\mathrm{Cu}$ concentration (i.e., $\mathrm{Nl}=1,8 \%$ per layer or $1 \%$ per slab concentration), the charge transfer between $\mathrm{Cu}$ and the oxide, $0.02 \mathrm{e} / \mathrm{at}$ when the $\mathrm{Cu}$ is in $l=1$ (Figure 4) and negligible when the $\mathrm{Cu}$ is at $l=2$ and $l=3$. This suggests that covalent bonds are formed between $\mathrm{Cu}$ and $\mathrm{Al}$ in the metal, see also Section 3.2.3.

Figure $5 \mathrm{~b}$ shows that the workfunction is higher relative to pure aluminium (covered with oxide) when the $\mathrm{Cu}$ atom is at the interface or sub-interface, in the $l=1, l=2$ or $l=3$ layer. We observe that the more stable the position of the dispersed $\mathrm{Cu}$ in the metal layer, the higher the workfunction, the ranking of stability and of workfunctions being $l=1(+0.3 \mathrm{eV})>l=3(+0.2 \mathrm{eV})>l=2(+0.1 \mathrm{eV})$. The formation of $\mathrm{Cu}-\mathrm{Al}$ bonds in the metal may explain this trend, as it is known that the increase of bond strength induces an increase in the workfunction [31]. The workfunction of pure Al covered by the oxide layer $(4.60 \mathrm{eV})$ is nearly recovered when the $\mathrm{Cu}$ atom is in $l=4(4.55 \mathrm{eV})$.

These results contrast with those obtained in the absence of oxide, for which $\mathrm{Cu}$ at low concentration has no effect on the $\mathrm{Al}(111)$ workfunction, whatever the $\mathrm{Cu}$ location at and underneath the surface.

\subsection{Electronic Density of States Analysis}

To better understand the effects of $\mathrm{Cu}$ on the electronic workfunction, the DOS analysis was performedin two extreme cases, $N l=1$, one copper atom and $N l=12$, one $\mathrm{Cu}$ monolayer in layer $l=1$ (see Figure 6 which shows a zoom on the valence band edges). The valence band edge of the oxide on $\mathrm{Al}$ with a single copper atom is slightly lower than that for the oxide on pure aluminium. As the charge transfer from $\mathrm{Cu}$ to the oxide is negligible, we attribute the VB stabilisation in the case of $N l=1$ to the formation of $\mathrm{Al}-\mathrm{Cu}$ bonds at the interface, that stabilize the levels of the interfacial $\mathrm{Al}$ atoms and in consequence the levels of the oxide at the interface.

We also observe that the presence of a full $\mathrm{Cu}$ layer at $l=1$ induces a shift in the VB of the oxide towards higher energies. This trend is in agreement with the formation of the interfacial dipole that induces a workfunction decrease. 
The energy gap (see Figure 6 and Table 2) varies as the workfunction, with values of $4.37 \mathrm{eV}$ for the monolayer copper, $4.48 \mathrm{eV}$ for pure aluminium (covered with oxide) and $4.53 \mathrm{eV}$ for $\mathrm{Al}$ (covered with oxide) with a single copper atom.

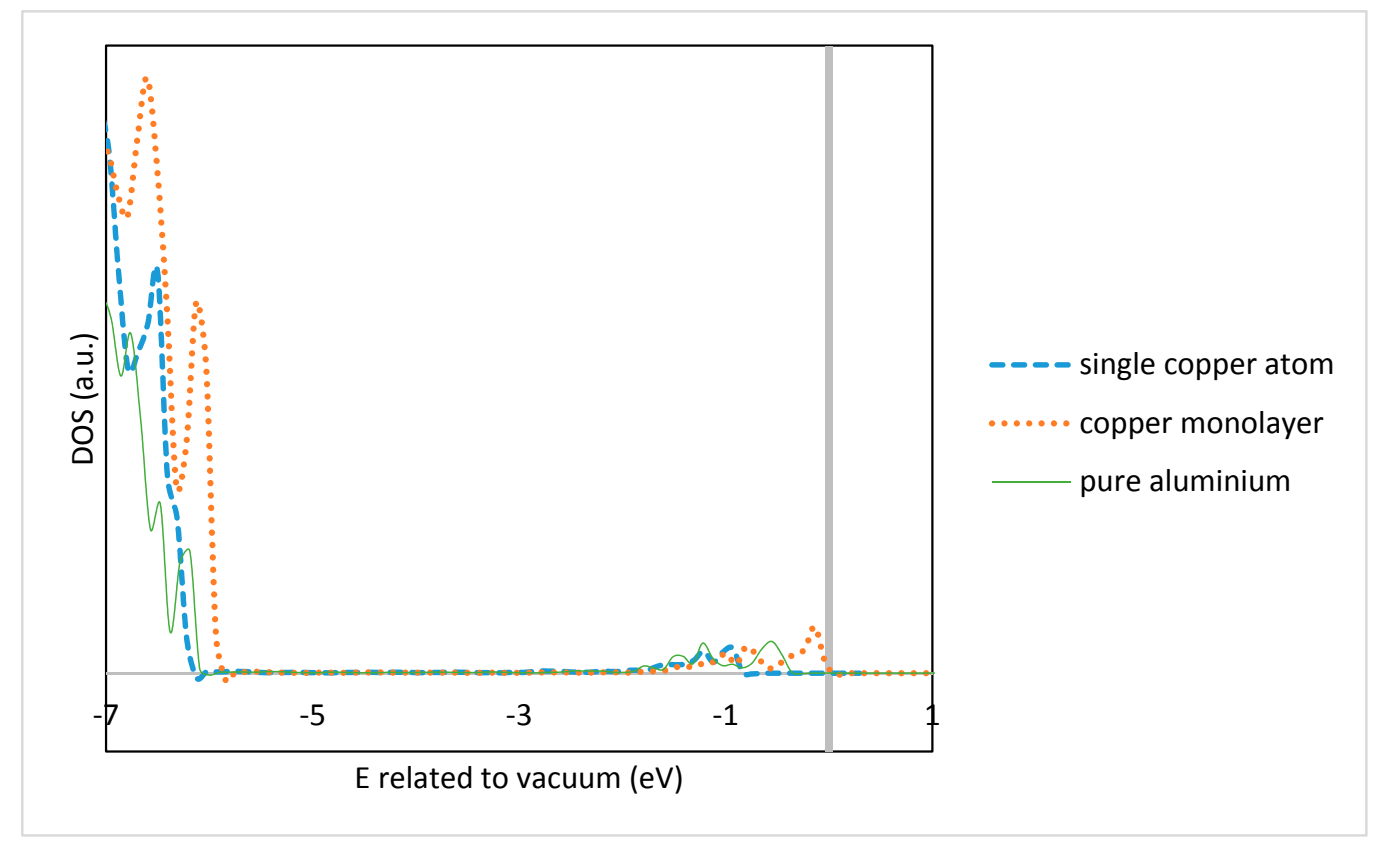

Figure 6. Comparison of the valence band edges of the inner layer of the supported oxide on pure $\mathrm{Al}, \mathrm{Al}$ with a single copper atom and $\mathrm{Al}$ with a copper monolayer in $l=1$ (a.u.: Arbitrary units). The reference energy is set to the vacuum level.

To summarize, (see Table 1) the present calculations suggest that the electronic levels inside the oxide depend on the presence and concentration of $\mathrm{Cu}$ at the near interface region of the $\mathrm{Al}$ metal: Segregation of $\mathrm{Cu}$ at low (respectively high) concentration under the passive film induces an increase (respectively decrease) of the electronic workfunction and of the electronic gap. Finally, the ability of the surface to transfer an electron to $\mathrm{O}_{2}$ was studied following the same procedure as in our previous works [6,39]. We found that the workfunction decrease calculated here is not high enough to induce an electron transfer towards $\mathrm{O}_{2}$.

In the absence of oxide, the segregation of the more noble, $\mathrm{Cu}$ metal, at high concentration at the $\mathrm{Al}(111)$ surface, induces an increase of the workfunction; we showed here that the presence of the oxide inverts this trend, as a charge transfer from the first metallic layers to the oxide induces a workfunction decrease.

Table 1. Summary of the calculated properties of the different models of passive film on $\mathrm{Al}$ and $\mathrm{AlCu}$ alloy considered in this work: Pure aluminium, a single copper at the oxide/metal interface, a copper monolayer in $l=1$, a copper monolayer in $l=2$.

\begin{tabular}{cccc}
\hline $\begin{array}{c}\text { Composition of the Metal } \\
\text { Layers Under the Oxide Film }\end{array}$ & $\begin{array}{c}\text { OxideBand } \\
\text { Gap }(\mathbf{e V})\end{array}$ & $\begin{array}{c}\text { Valence Band } \\
\text { Level/Vacuum (eV) }\end{array}$ & $\begin{array}{c}\text { Workfunction } \\
\text { 申e (eV) }\end{array}$ \\
\hline Pure Al & 4.48 & -6.00 & 4.60 \\
$N l=1 \mathrm{Cu}$ & 4.53 & -6.09 & 4.91 \\
$N l=12 \mathrm{Cu}, l=1$ & 4.37 & -5.84 & 4.25 \\
$N l=12 \mathrm{Cu}, l=2$ & $4.78^{*}$ & $-6.44^{*}$ & $4.00^{*}$ \\
\hline
\end{tabular}

${ }^{*}$ Data not shown in the Figures. 


\subsection{Copper Segregation in GP Zones}

Experimental and theoretical results have shown that the GP1 zones are more stable than the GP2 [15]. We therefore focus on the GP1 zones only. We start from the idea developed by Benali [15] indicating an increased stability of the system by a multilayer segregation instead of a monolayer segregation. We thus model the GP1 zones with a cluster of 3 copper atoms in the (100) plane of the metallic slab of aluminium (111) covered with the oxide film. In GP1 zones, clusters with 3 copper atoms in the (100) plane are separated by 7 aluminium (100) planes. As seen in the previous section, two localizations ( $l=1$ and $l=2)$ of copper are favoured. We consider two configurations or cluster orientations: In the first configuration, two copper atoms are in the plane $l=1$ and the third atom in the plane $l=2$, and in configuration 2 one copper atom is in the plane $l=1$ and the other two in the plane $l=2$. Configurations 2 and 1 are thus symmetrical configurations. We also investigate two positions: Position 1, or interface position, when the nearest copper to the interface is in $l=1$ position and position 2, or sub-interface position, when the nearest copper to the interface copper is in $l=2$ (see Figure 7).

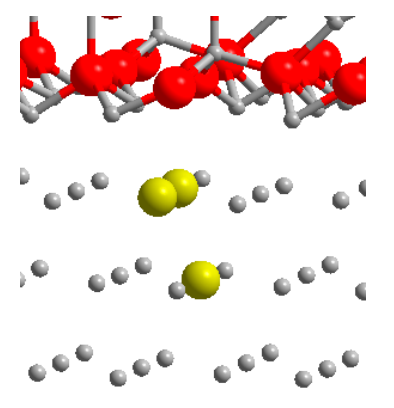

(a)
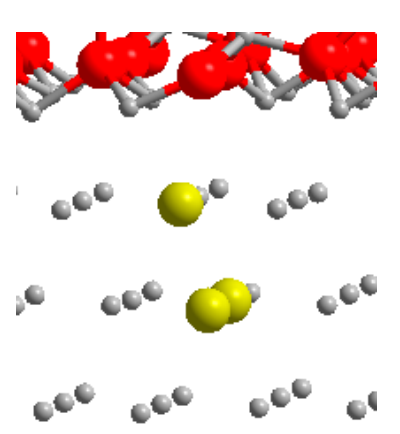

(b)

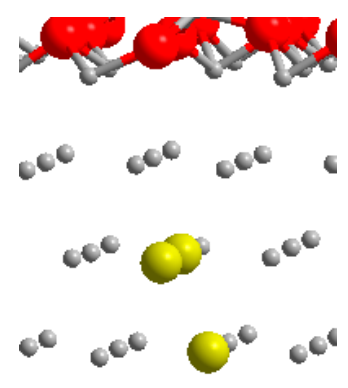

(c)
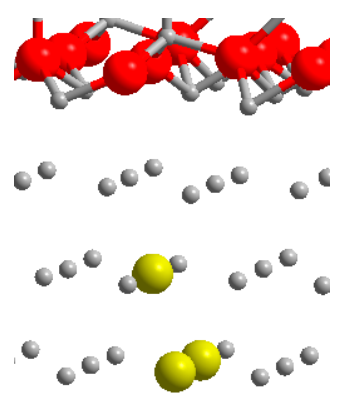

(d)

Figure 7. Models of GP1 zone considered. (a) Configuration 1 and position 1; (b) configuration 2 and position 1; (c) configuration 1 and position 2; (d) configuration 2 and position 2.

Table 2 shows the results obtained for the copper segregation energies (in $\mathrm{eV}$ per atom) of the GP1 zones calculated from the Equation (2) as a function of their in-depth positions relative to the interface and for the different configurations considered. The interface position (1) is $40 \mathrm{meV}$ more stable than the sub-interface position (2) for configuration 1 and $20 \mathrm{meV}$ for configuration 2 . In addition, configuration 1 is also always more stable than configuration 2, by $40 \mathrm{meV} /$ at for position 1 and by about $30 \mathrm{meV} /$ at for position 2 . We have a system stabilization by a bilayer segregation in interface and sub-interface. The most favourable position is the position 1 (interface position) and the configuration 1 (two copper atoms in the upper position), as shown in Figure 7a. So, the most stable position of the copper doped layers is in the interface under the oxide film, with segregation energy of $-160 \mathrm{meV} /$ at (calculated for the limit of the isolated atom in the bulk). By comparison, we calculated bulk clusterisation energy for both configurations and found $-60 \mathrm{mV} / \mathrm{at}$. The three copper atoms energy in a monolayer under the oxide film is $-140 \mathrm{meV} /$ at while the most stable multilayer is $-160 \mathrm{meV} / \mathrm{at}$. Therefore, the bilayer formation is slightly favoured over the monolayer one. These results confirm the tendency to formation and segregation of GP1 just below the metal/oxide interface.

Table 2 also reports the segregation energies in absence of oxide layer. It appears that position 2 with the highest copper content in the layer underneath the surface $(l=2)$ is the most stable position in absence of oxide, whereas the position 1 , with the highest $\mathrm{Cu}$ in the interface layer $(l=1)$, is the most stable in presence of oxide. Furthermore, whereas for position 2, configuration 1 and 2 are isoenergetic in absence of oxide, the configuration 1, position 1 is clearly the most favored configuration under the oxide. 
It is interesting to compare the energy of three $\mathrm{Cu}$ atoms coplanar in $l=1$, under the oxide film to that of the GP1 formation. The energy associated to three copper atoms under the oxide film is $-140 \mathrm{meV} /$ at while for the GP1 it is $-160 \mathrm{meV} /$ at. These results show a tendency to formation and segregation of GP1 in configuration 1 and position1 just below the metal/oxide interface. This suggests that clusterization in the bilayer is stabilized as compared to the monolayer formation.

Table 2. Segregation energy (in eV/at) for the formation of copper aggregates in an aluminum slab covered by an oxide film according to the position and configuration of the doped layers. See Figure 7 for the illustration of the different configurations.

\begin{tabular}{lccccc}
\hline Configuration & Position 1 & $\begin{array}{c}\text { Position 1 in } \\
\text { Absence of Oxide }\end{array}$ & Position 2 & $\begin{array}{c}\text { Position 2 in } \\
\text { Absence of Oxide }\end{array}$ & Bulk Position \\
\hline Configuration 1 & -0.16 & -0.08 & -0.12 & -0.13 & -0.06 \\
Configuration 2 & -0.11 & -0.08 & -0.09 & -0.12 & -0.06 \\
\hline
\end{tabular}

\section{Discussion and Conclusions}

In this work, $\mathrm{Al}-\mathrm{Cu}$ alloys covered by an ultrathin, hydroxylated $\mathrm{Al}_{2} \mathrm{O}_{3}$ film have been modelled. We investigated different distributions of $\mathrm{Cu}$ in $\mathrm{Al}$ : Pure $\mathrm{Al}, \mathrm{Cu}$ segregated at the oxide-metal interface at different concentrations, and GP zones. In the model, aluminium atoms are substituted by copper atoms in the metallic layers underneath the oxide film.

Copper segregation is favoured in the first (respectively second) layer underneath the oxide film at low (respectively high) concentration. The presence of the oxide reinforces the tendency to $\mathrm{Cu}$ segregation just underneath the $\mathrm{Al}$ surface (interface with oxide) as evidenced for oxide-free $\mathrm{Al}$ [15].

The study of the electronic properties revealed two different regimes:

Copper at low concentration $(\mathrm{Nl}=1)$ at the metal/oxide interface induces an increase in the workfunction as compared to pure $\mathrm{Al} / \mathrm{Al}_{2} \mathrm{O}_{3}$, whereas no significant modification of the workfunction is observed when $\mathrm{Cu}$ at low concentration $(<8 \%)$ segregates at the $\mathrm{Al}$ surface.

At high copper concentration, for a $\mathrm{Cu} M L$ at the metal/oxide interface or sub-interface, the oxide electronic levels are destabilised by a charge transfer from the metal (copper atoms) to the oxide, inducing a decrease of the electronic workfunction. These results are opposite to that obtained without the oxide film where the workfunction increases when the copper monolayer is at the $\mathrm{Al}$ surface or sub-surface.

These results can be compared to those obtained by Huang et al. [31], who found that $\mathrm{Ni}-\mathrm{Cu}$ alloys have a workfunction increasing with the $\mathrm{Ni}$ content (the more noble metal). In acidic solution, no oxide layer is formed on the alloy surface, the resistance to corrosion increases with the Ni content, and this was attributed to the increase of workfunction. However, in neutral solution, the alloys are covered with an oxide film, and the corrosion resistance increased with the $\mathrm{Cu}$ content in the alloy. We are now able to explain that the presence of an oxide film might inverse the tendency of workfunction increasing with the increase in the noble element.

The important decrease of the workfunction of $0.4-0.6 \mathrm{eV}$ observed at full $\mathrm{Cu}$ layer suggests that the system is less resistant to electron transfer.

The study of the GP zones showed that multilayers are slightly more stable than the monolayer.

Further work on $\mathrm{Al}_{2} \mathrm{Cu}$ covered with $\mathrm{Al}_{2} \mathrm{O}_{3}$ are in progress to complete the present study in taking in consideration intermetallic phases. Future works will also include the presence of $\mathrm{Cu}$ in the oxide.

Acknowledgments: GENCI is acknowledged for high performance calculations in the national (IDRIS, CINES) centres under the project c2016082217. Pauline Cornette thanks doctoral school ED388 (UPMC and PSL) for a PhD grant.

Author Contributions: Pauline Cornette, Dominique Costa and Philippe Marcus conceived the modeling approach. Pauline Cornette performed the calculations; Pauline Cornette and Dominique Costa analyzed the data; Pauline Cornette wrote the paper; Dominique Costa and Philippe Marcus read and corrected the paper. 
Conflicts of Interest: The authors declare no conflict of interest. The founding sponsors had no role in the design of the study; in the collection, analyses, or interpretation of data; in the writing of the manuscript, and in the decision to publish the results.

\section{References}

1. Vargel, C. Corrosion of Aluminium, 1st ed.; Elsevier: Amsterdam, The Netherlands, 2004.

2. Strohmeier, B.R. An ESCA method for determining the oxide thickness on aluminum alloys. Surf. Interface Anal. 1990, 15, 51-56. [CrossRef]

3. Van den Brand, J.; Sloof, W.G.; Terryn, H.; De Wit, J.H.W. Correlation between hydroxyl fraction and O/Al atomic ratio as determined from XPS spectra of aluminium oxide layers. Surf. Interface Anal. 2004, 36, 81-88. [CrossRef]

4. McCafferty, E.; Wightman, J.P. Determination of the concentration of surface hydroxyl groups on metal oxide films by a quantitative XPS method. Surf. Interface Anal. 1998, 26, 549-564. [CrossRef]

5. Vargel, C. Corrosion De L'aluminium; Dunod: Paris, France, 1999.

6. Costa, D.; Ribeiro, T.; Mercuri, F.; Pacchioni, G.; Marcus, P. Atomistic Modeling of Corrosion Resistance: A First Principles Study of $\mathrm{O}_{2}$ Reduction on the $\mathrm{Al}(111)$ Surface Covered with a Thin Hydroxylated Alumina Film. Adv. Mater. Interfaces 2014, 1, 1300072. [CrossRef]

7. Marcus, P. (Ed.) Corrosion Mechanisms in Theory and Practice, 3rd ed.; CRC Press: Boca Raton, FL, USA, 2012.

8. Taylor, C.D.; Marcus, P. Theoretical Methods in Modeling Corrosion; Wiley and Sons: New York, NY, USA, 2015.

9. Kokalj, A.; Peljhan, S.; Finsgar, M.; Milosev, I. What Determines the Inhibition Effectiveness of ATA, BTAH, and BTAOH Corrosion Inhibitors on Copper? J. Am. Chem. Soc. 2010, 132, 16657-16668. [CrossRef] [PubMed]

10. Milosev, I.; Kovacevic, N.; Kovac, J.; Kokalj, A. The roles of mercapto, benzene and methyl groups in the corrosion inhibition of imidazoles on copper: I. Experimental characterization. Corros. Sci. 2015, 98, 107-118. [CrossRef]

11. Taylor, C.D. Atomistic Modeling of Corrosion Events at the Interface between a Metal and Its Environment. Int. J. Corros. 2012, 2012, 204640. [CrossRef]

12. Chiter, F.; Lacaze-Dufaure, C.; Tang, H.; Pebere, N. DFT studies of the bonding mechanism of 8-hydroxyquinoline and derivatives on the (111) aluminum surface. Phys. Chem. Chem. Phys. 2015, 17, 22243-22258. [CrossRef] [PubMed]

13. Poberžnik, M.; Kokalj, A. Origin of Surprising Attractive Interactions between Electronegative Oxygen Adatoms on Aluminum Surfaces. J. Phys. Chem. C 2016, 120, 25915-25922. [CrossRef]

14. Hoshino, T.; Fujima, N.; Asato, M.; Tamura, R. Medium-ranged interactions of transition-metal (3d and 4d) impurity pairs in $\mathrm{Al}$ and atomic structures of Al-rich Al-transition-metal alloys. J. Alloys Compd. 2007, 434-435, 572-576. [CrossRef]

15. Benali, A.; Lacaze-Dufaure, C.; Morillo, J. Density functional study of copper segregation in aluminum. Surf. Sci. 2011, 605, 341-350. [CrossRef]

16. Braunovic, M.; Alexandrov, N. Intermetallic compounds at aluminum-to-copper electrical interfaces: Effect of temperature and electric current. IEEE Trans. Compon. Packag. Manuf. Technol. Part A 1994, 17, 78-85. [CrossRef]

17. Lee, M.J.G.; Gensch, M.; Shkrebtii, A.I.; Herrmann, T.; Richter, W.; Esser, N.; Hofmann, P. Surface states and resonances on $\mathrm{Al}(110)$ : Ultraviolet photoemission spectroscopy and ab initio calculations. Phys. Rev. B 2005, 72, 85408. [CrossRef]

18. Vaithyanathan, V.; Wolverton, C.; Chen, L.Q. Multiscale Modeling of Precipitate Microstructure Evolution. Phys. Rev. Lett. 2002, 88, 125503. [CrossRef] [PubMed]

19. Wolverton, C.; Ozolinšs, V. Entropically Favored Ordering: The Metallurgy of $\mathrm{Al}_{2} \mathrm{Cu}$ Revisited. Phys. Rev. Lett. 2001, 86, 5518-5521. [CrossRef] [PubMed]

20. Wolverton, C.; Ozolinšs, V. First-principles aluminum database: Energetics of binary Al alloys and compounds. Phys. Rev. B 2006, 73, 144104. [CrossRef]

21. Wolverton, C.; Yan, X.-Y.; Vijayaraghavan, R.; Ozoliš, V. Incorporating first-principles energetics in computational thermodynamics approaches. Acta Mater. 2002, 50, 2187-2197. [CrossRef]

22. Vaithyanathan, V.; Wolverton, C.; Chen, L.Q. Multiscale modeling of $\theta^{\prime}$ precipitation in Al-Cu binary alloys. Acta Mater. 2004, 52, 2973-2987. [CrossRef] 
23. Wolverton, C.; Ozolins, V.; Zunger, A. Short-range-order types in binary alloys: A reflection of coherent phase stability. J. Phys. Condens. Matter. 2000, 12, 2749. [CrossRef]

24. Zhou, W.; Liu, L.; Li, B.; Song, Q.; Wu, P. Structural, Elastic, and Electronic Properties of Al-Cu Intermetallics from First-Principles Calculations. J. Electron. Mater. 2009, 38, 356-364. [CrossRef]

25. Wang, S.Q.; Schneider, M.; Ye, H.Q.; Gottstein, G. First-principles study of the formation of Guinier-Preston zones in Al-Cu alloys. Scr. Mater. 2004, 51, 665-669. [CrossRef]

26. Ye, M.; Zhang, Y.; Li, L.; Liu, R.; Qiu, M.; Xu, C.; Chen, X. A periodic density functional theory calculation: The structure of isolated copper (I) oxide species on $\gamma-\mathrm{Al}_{2} \mathrm{O}_{3}(110)$ surface and its adsorption ability toward thiophene and benzene. Appl. Surf. Sci. 2015, 346, 165-171. [CrossRef]

27. Wang, J.; Wolverton, C.; Müller, S.; Liu, Z.-K.; Chen, L.-Q. First-principles growth kinetics and morphological evolution of $\mathrm{Cu}$ nanoscale particles in Al. Acta Mater. 2005, 53, 2759-2764. [CrossRef]

28. Mohamed, I.F.; Yonenaga, Y.; Lee, S.; Edalati, K.; Horita, Z. Age hardening and thermal stability of Al-Cu alloy processed by high-pressure torsion. Mater. Sci. Eng. A 2015, 627, 111-118. [CrossRef]

29. Lanthony, C.; Ducéré, J.M.; Rouhani, M.D.; Hemeryck, A.; Estève, A.; Rossi, C. On the early stage of aluminum oxidation: An extraction mechanism via oxygen cooperation. J. Chem. Phys. 2012, 137, 94707. [CrossRef] [PubMed]

30. Baran, J.D.; Grönbeck, H.; Hellman, A. Mechanism for Limiting Thickness of Thin Oxide Films on Aluminum. Phys. Rev. Lett. 2014, 112, 146103. [CrossRef] [PubMed]

31. Huang, X.C.; Lu, H.; Li, D.Y. Understanding the corrosion behavior of isomorphous Cu-Ni alloy from its electron work function. Mater. Chem. Phys. 2016, 173, 238-245. [CrossRef]

32. Perdew, J.P.; Chevary, J.A.; Vosko, S.H.; Jackson, K.A.; Pederson, M.R.; Singh, D.J.; Fiolhais, C. Atoms, molecules, solids, and surfaces: Applications of the generalized gradient approximation for exchange and correlation. Phys. Rev. B 1992, 46, 6671-6687. [CrossRef]

33. Perdew, J.P.; Burke, K.; Ernzerhof, M. Generalized Gradient Approximation Made Simple. Phys. Rev. Lett. 1996, 77, 3865-3868. [CrossRef] [PubMed]

34. Kresse, G.; Hafner, J. Ab initio molecular-dynamics simulation of the liquid-metal amorphous-semiconductor transition in germanium. Phys. Rev. B 1994, 49, 14251-14269. [CrossRef]

35. Blöchl, P.E.; Jepsen, O; Andersen, O.K. Improved tetrahedron method for Brillouin-zone integrations. Phys. Rev. B 1994, 49, 16223-16233. [CrossRef]

36. Kresse, G.; Joubert, D. From ultrasoftpseudopotentials to the projector augmented-wave method. Phys. Rev. B 1999, 59, 1758-1775. [CrossRef]

37. Monkhorst, H.J.; Pack, J.D. Special points for Brillouin-zone integrations. Phys. Rev. B 1976, 13, 5188-5192. [CrossRef]

38. Grimme, S. Semiempirical GGA-type density functional constructed with a long-range dispersion correction. J. Comput. Chem. 2006, 27, 1787-1799. [CrossRef] [PubMed]

39. Costa, D.; Ribeiro, T.; Cornette, P.; Marcus, P. DFT Modeling of Corrosion Inhibition by Organic Molecules: Carboxylates as Inhibitors of Aluminum Corrosion. J. Phys. Chem. C 2016, 120, 28607-28616. [CrossRef]

40. Eastment, R.M.; Mee, C.H.B. Work function measurements on (100), (110) and (111) surfaces of aluminium. J. Phys. F Met. Phys. 1973, 3, 1738. [CrossRef]

41. Bader, R.F.W. A Bond Path: A Universal Indicator of Bonded Interactions. J. Phys. Chem. A 1998, 102, 7314-7323. [CrossRef]

42. Hoshino, T.; Asato, M.; Tanaka, S.; Nakamura, F.; Fujima, N. First-principles calculations for stability of atomic structures of Al-rich $\mathrm{AlX}(\mathrm{X}=\mathrm{Sc}-\mathrm{Zn})$ alloys, including AlMn quasicrystal: II. Medium-ranged interactions of $X$ pairs in Al. Intermetallics 2006, 14, 913-916. [CrossRef]

(C) 2017 by the authors. Licensee MDPI, Basel, Switzerland. This article is an open access article distributed under the terms and conditions of the Creative Commons Attribution (CC BY) license (http:/ / creativecommons.org/licenses/by/4.0/). 